\title{
Aerosol therapy in relation to retinopathy of prematurity in mechanically ventilated preterm infants
}

\author{
Mei-Chin Yang ${ }^{1}$, Hsiu-Feng Hsiao ${ }^{1}$, Hsiu-Li Tseng ${ }^{1}$, Ya-Wen Chiu ${ }^{2}$ and Yi-Hao Weng ${ }^{1,3^{*}}$ (0)
}

\begin{abstract}
Background: Aerosol administration is increasingly being used as a therapeutic intervention for mechanically ventilated preterm infants. However, the effects of inhalation therapy on retinopathy of prematurity (ROP) have not yet been explored.

Methods: A retrospective cohort study was conducted in a tertiary level neonatal intensive care unit (NICU) from 2011 to 2013. All preterm infants with a gestational age (GA) of 24 29 weeks receiving invasive intubation for more than 1 week in the NICU were included. Infants with severe congenital anomalies were excluded. ROP was defined as stage II or greater according to medical records by ophthalmologists. A multivariate logistic regression model was used to estimate the risk of ROP in relation to inhalation therapy after adjusting for confounders.

Results: In total, 205 infants were enrolled in this study, including 154 with inhalation therapy and 51 without inhalation therapy. Univariate analyses showed an association of inhalation with the following characteristics: sex $(p=0.047)$, GA $(p=0.029)$, sepsis $(p=0.047)$, bronchopulmonary dysplasia (BPD) $(p<0.001)$, and $\operatorname{ROP}(p=0.001)$. Furthermore, logistic regression analysis indicated that inhalation therapy was an independent risk factor for ROP (odds ratio $(\mathrm{OR})=2.639 ; 95 \%$ confidence interval $(\mathrm{Cl})=1.050 \sim 6.615)$. In addition, infants with a GA of $24 \sim 25$ weeks $(\mathrm{OR}=6.063 ; 95 \% \mathrm{Cl}=2.482 \sim 14.81)$ and $26 \sim 27$ weeks $(\mathrm{OR}=3.825 ; 95 \% \mathrm{Cl}=1.694 \sim 8.638)$ were at higher risk of ROP than those with a GA of 28 29 weeks. Other factors - including sex, sepsis, BPD, and delivery mode - did not carry significant risk.
\end{abstract}

Conclusion: Aerosol therapy with pure oxygen delivery is associated with ROP. Clinicians should exercise great caution when conducting aerosol therapy with excess oxygen in mechanically ventilated preterm infants.

Keywords: GA, Aerosol therapy, ROP, HFV, iNO

\section{Introduction}

Aerosol inhalation has been widely used to manage pulmonary diseases of children and adults. However, the distribution of particle deposition in the airway is different between infants and adults [1]. Recently, inhalation therapy is increasingly administrated to preterm infants. Several inhalants are used for mechanically ventilated infants, such as bronchodilators, corticosteroids, xanthine derivatives, mucoactive agents, and antibiotics. Inhaled

\footnotetext{
* Correspondence: yihaoweng@cgmh.org.tw

'Department of Respiratory Therapy, Chang Gung Memorial Hospital, Chang Gung University, Taoyuan, Taiwan

${ }^{3}$ Department of Pediatrics, Chang Gung Memorial Hospital, Chang Gung University College of Medicine, 199 Dunhua North Road, Taipei 105, Taiwan Full list of author information is available at the end of the article
}

bronchodilators help relieve airway constriction and improve lung compliance in premature infants with respiratory distress [2-4] and bronchopulmonary dysplasia (BPD) $[5,6]$. The frequency and treatment duration of inhaled bronchodilators markedly vary because of no evidence-based guidelines [7]. In addition to bronchodilators, inhaled corticosteroids and xanthine derivatives have replaced systemic ones for managing BPD in preterm infants $[8,9]$. Furthermore, the use of inhaled mucoactive medications makes secretions easier to transport and increases the efficiency of cough or mucus clearance, since secretion clearance is hampered by weakness and restrictive lungs [10]. However, the role of

(C) The Author(s). 2019 Open Access This article is distributed under the terms of the Creative Commons Attribution 4.0 International License (http://creativecommons.org/licenses/by/4.0/), which permits unrestricted use, distribution, and 
mucoactive agents in pulmonary critical care for mechanically ventilated preterm infants is not yet clear [11].

Retinopathy of prematurity (ROP) is a common disease of premature infants [12]. Exposing premature infants to supplemental oxygen is an important risk factor for developing ROP [13, 14]. Increased duration and number of hyperoxia events may increase the risk of ROP $[15,16]$. Therefore, consensus guideline for resuscitation of preterm infants has been revised to deliver a low fraction of inspired oxygen [17].

Excess oxygen may be delivered to premature infants during inhalation therapy. However, any correlation of ROP with inhalation therapy has never been determined. Thus in the current study, we explored whether excess oxygen via inhalation therapy can cause ROP in extremely premature infants. The findings of this study provide clinical implications for therapeutic strategies to avoid the development of ROP.

\section{Materials and methods}

\section{Enrollment of subjects}

This retrospective study was conducted from June 1, 2011 to December 31, 2013 in the neonatal intensive care unit (NICU) of Chang Gung Memorial Hospital, a tertiary referral center in northern Taiwan. During this study period, preterm infants (with a gestational age (GA) of $24 \sim 29$ weeks) who received invasive intubation for more than 7 days in the NICU of Chang Gung Memorial Hospital were included. The exclusion criteria included neonates with significant congenital malformation and referral neonates who had been admitted to another NICU for more than 1 day. Infants who did not receive screening for ROP were not enrolled, including death before ROP screening.

\section{Aerosol therapy}

Infants who received aerosol administration of therapeutic drugs for at least 1 week during the first month of life were categorized as the aerosol therapy group. Inhaled medications were delivered through a commercially disposable nebulizer by a jet $(100 \%$ compressed oxygen forced through a small hole into an adjacent reservoir containing medication in solution) [18]. When the aerosols were delivered to the endotracheal tube, the fraction of oxygen concentration was measured to estimate the final fraction of inspired oxygen $\left(\mathrm{FiO}_{2}\right)$. The average readouts of $\mathrm{FiO}_{2}$ in the endotracheal tube were $48.1 \%$ when receiving $21 \%$ of oxygen, $52.0 \%$ when receiving $25 \%$ of oxygen, $56.9 \%$ when receiving $30 \%$ of oxygen, $58.7 \%$ when receiving $40 \%$ of oxygen, $62.4 \%$ when receiving $50 \%$ of oxygen, $68.0 \%$ when receiving $60 \%$ of oxygen, $77.7 \%$ when receiving $70 \%$ of oxygen, $84.1 \%$ when receiving $80 \%$ of oxygen, and $92.3 \%$ when receiving $90 \%$ of oxygen. Aerosol therapy was routinely performed for a period of 15 20 min every $8 \mathrm{~h}$.

\section{Data collection}

Clinical characteristics of enrolled subjects were recorded, including demographic characteristics, perinatal history, and outcomes. Mortality was defined as death after the screening of ROP at 1 month of age. Screening for ROP was performed by trained pediatric ophthalmologists using indirect ophthalmoscopy. The first time for ROP screening was 1 month of age. In this study, an infant with ROP was defined as stage II or greater for at least one eye by the International Classification of ROP [19].

\section{Statistical analyses}

Statistics were compiled using a commercially available program (SPSS 19.0 for Windows, SPSS, Chicago, IL, USA). Categorical variables were analyzed using the Chisquared test or Fisher's exact test. For comparison of quantitative variables between groups, the null hypothesis that there was no difference between groups was tested by a one-way analysis of variance (ANOVA). A multivariate logistic regression model was used to estimate the risk of ROP in relation to inhalation therapy after adjusting for possible confounders. Odds ratio (OR) and $95 \%$ confidence interval $(\mathrm{CI})$ were expressed after adjusting for the control variables. Significance was defined as $p<0.05$.

\section{Results}

In total, 205 preterm infants were eligible for enrollment, including 54 infants with a GA of $24 \sim 25$ weeks, 69 infants with a GA of 26 27 weeks, and 82 infants with a GA of $28 \sim 29$ weeks. The incidence of ROP was $55.6 \%$ in infants with a GA of $24 \sim 25$ weeks, $44.9 \%$ in those with a GA of $26 \sim 27$ weeks, and $14.6 \%$ in those with a GA of $28 \sim 29$ weeks (Fig. 1).

There were 154 infants $(75.1 \%)$ who received aerosol therapy via an endotracheal tube. Drugs used for aerosol therapy included bronchodilators (ipratropium bromide, fenoterol, and salbutamol) and mucoactive agents

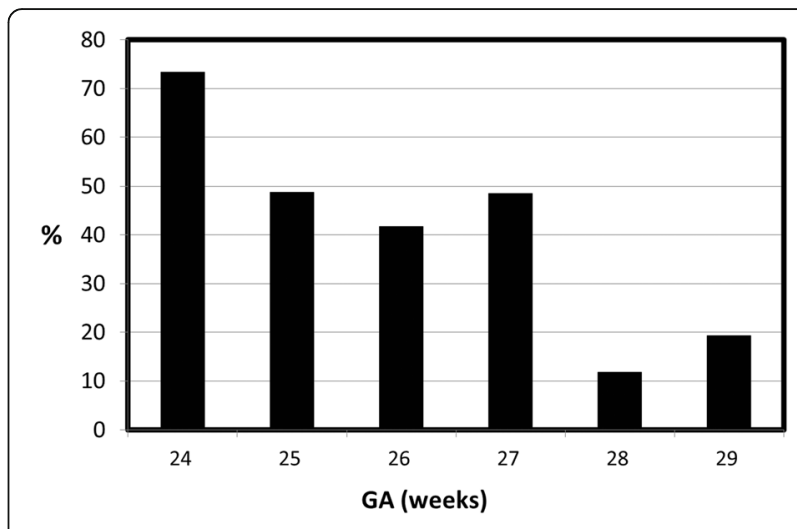

Fig. 1 Incidence of ROP by GA ( $N=205)$ 
(acetylcysteine and sodium bicarbonate). The most commonly used inhalation drug was acetylcysteine (99/154= 64.3\%). The use for bronchodilators and mucoactive agents was to decrease airway resistance and to promote mucin breakdown, respectively [20].

Demographic characteristics of enrolled infants are shown in Table 1. There were significant differences in sex and GA between infants with and without aerosol therapy. Males were more common among infants with aerosol therapy. Furthermore, the incidence of aerosol therapy was inversely proportional to GA: $85.2 \%$ at GA of $24 \sim 25$ weeks, $78.2 \%$ at GA of $26 \sim 27$ weeks, and $65.9 \%$ at GA of 28 29 weeks. Overall, the mortality rate after 1 month of age was $5.4 \%$. There was no significant difference in the mortality between the aerosol and control groups. All deaths in both groups were related with sepsis.

Table 2 illustrates the association between ROP and settings of mechanical ventilation. There was a significant correlation of ROP with the following factors - aerosol therapy, high frequency ventilation (HFV), inhaled nitric oxide (iNO), and the duration of intubation. In specific, ROP was more common in infants with aerosol therapy, iNO, use of HFV longer than 1 week, and intubation period more than 6 weeks. The relationship between ROP and aerosol therapy by three categories of GA is shown in Table 3. There was a trend of increasing ROP among infants with aerosol therapy in all categories of GA.

A risk assessment of ROP was conducted using a multivariate logistic regression model (Table 4). Adjusted confounders included sex, aerosol therapy, GA, iNO, HFV, and intubation period. The regression analysis showed that inhalation therapy carried a greater risk of ROP. In addition, infants with a GA of $24 \sim 27$ weeks were at greater risk of ROP than those with a GA of 28 29 weeks. Other factors - including sex, HFV, iNO, and intubation period - did not carry significant risk.

Table 1 Demographic data of enrolled participants $(N=205)$

\begin{tabular}{llll}
\hline Aerosol therapy & No & Yes & $p$ value \\
Number & 51 & 154 & \\
\hline Sex (\%) & & & 0.047 \\
$\quad$ Male & $22(19.5)$ & $91(80.5)$ & \\
$\quad$ Female & $29(31.5)$ & $63(68.5)$ & \\
$\begin{array}{l}\text { Delivery mode (\%) } \\
\text { Vaginal }\end{array}$ & $30(31.3)$ & $108(68.7)$ & 0.136 \\
$\quad$ Cesarean section & $21(21.7)$ & $46(78.3)$ & \\
GA (week) (\%) & & & 0.029 \\
$24 \sim 25$ & $8(14.8)$ & $46(85.2)$ & \\
$26 \sim 27$ & $15(21.7)$ & $54(78.3)$ & \\
$28 \sim 29$ & $28(34.1)$ & $54(65.9)$ & \\
Mortality & $2(3.9)$ & $9(5.8)$ & 0.735 \\
\hline
\end{tabular}

Table 2 Relationship between ROP and settings of mechanical ventilation $(N=205)$

\begin{tabular}{|c|c|c|c|}
\hline \multirow[t]{2}{*}{ ROP } & \multirow{2}{*}{$\begin{array}{l}\text { Yes } \\
N=73 \\
n(\%)\end{array}$} & \multirow{2}{*}{$\begin{array}{l}\text { No } \\
N=132 \\
n(\%)\end{array}$} & \multirow[t]{2}{*}{$p$ value } \\
\hline & & & \\
\hline Aerosol therapy & & & 0.001 \\
\hline Yes & $65(89.0)$ & $89(67.4)$ & \\
\hline No & $8(11.0)$ & $43(32.6)$ & \\
\hline Duration of HFV (day) & & & $<0.001$ \\
\hline Never use & $15(20.5)$ & $65(49.2)$ & \\
\hline $1 \sim 7$ & $19(26.1)$ & $33(25.1)$ & \\
\hline $8 \sim 28$ & $15(20.5)$ & $14(10.6)$ & \\
\hline$>28$ & $24(32.9)$ & $20(15.1)$ & \\
\hline iNO & & & 0.009 \\
\hline Yes & $10(13.7)$ & $5(3.8)$ & \\
\hline No & $63(86.3)$ & $127(96.2)$ & \\
\hline Duration of intubation (day) & & & $<0.001$ \\
\hline $8 \sim 21$ & $11(15.1)$ & $44(33.5)$ & \\
\hline $22 \sim 42$ & $20(27.4)$ & $53(40.5)$ & \\
\hline $43 \sim 84$ & $15(20.5)$ & $15(11.5)$ & \\
\hline$>84$ & $27(37.0)$ & $19(14.5)$ & \\
\hline
\end{tabular}

\section{Discussion}

This study depicts the association between aerosol therapy and ROP among mechanically ventilated preterm infants. To our best knowledge, this is the first study to investigate the potential impact of aerosol therapy on the risk of ROP. Our findings suggest that aerosol administration of therapeutic drugs via an endotracheal tube in combination with pure oxygen may result in harmful effects of ROP in infants with a GA of 24 29 weeks.

ROP is a multifactorial disease. One of the most significant risk factors for ROP is a low GA, as shown in

Table 3 Relationship between ROP and aerosol therapy by GA $(N=205)$

\begin{tabular}{llll}
\hline ROP & Yes & No & $p$ value \\
\hline $\begin{array}{l}\text { Aerosol therapy } \\
\text { (GA 24 } \sim 25 \text { wk., } N=54)\end{array}$ & $N=30(\%)$ & $N=24(\%)$ & 0.120 \\
Yes & $28(93.9)$ & $18(75.0)$ & \\
No & $2(6.7)$ & $6(25.0)$ & \\
Aerosol therapy & $N=31(\%)$ & $N=38(\%)$ & 0.385 \\
(GA 26 $\sim 27$ wk., $N=69)$ & & & \\
Yes & $26(83.9)$ & $28(73.7)$ & 0.051 \\
No & $5(16.1)$ & $10(26.3)$ & \\
Aerosol therapy & $N=12(\%)$ & $N=70(\%)$ & \\
(GA 28 $\sim 29$ wk., N=82) & & $43(61.4)$ & \\
Yes & $11(91.7)$ & $27(38.6)$ & \\
No & $1(8.3)$ & & \\
\hline
\end{tabular}


Table 4 Risk assessment for ROP by a logistic regression analysis

\begin{tabular}{|c|c|c|c|}
\hline Risk factor & OR & $95 \% \mathrm{Cl}$ & $p$ value \\
\hline Male & 0.592 & $0.301 \sim 1.165$ & 0.129 \\
\hline Aerosol therapy & 2.828 & $1.069 \sim 7.484$ & 0.036 \\
\hline iNO & 2.084 & $0.585 \sim 7.426$ & 0.257 \\
\hline \multicolumn{4}{|l|}{ GA (week) } \\
\hline $24 \sim 25$ & 4.001 & $1.518 \sim 10.55$ & 0.005 \\
\hline $26 \sim 27$ & 3.920 & $1.688 \sim 9.104$ & 0.001 \\
\hline $28 \sim 29$ & reference & & \\
\hline \multicolumn{4}{|c|}{ Duration of HFV (day) } \\
\hline$>28$ & 1.610 & $0.566 \sim 4.580$ & 0.372 \\
\hline $8 \sim 28$ & 2.111 & $0.719 \sim 6.197$ & 0.174 \\
\hline $1 \sim 7$ & 1.823 & $0.763 \sim 4.357$ & 0.177 \\
\hline Never use & reference & & \\
\hline \multicolumn{4}{|c|}{ Duration of intubation (day) } \\
\hline$>84$ & 1.971 & $0.569 \sim 6.832$ & 0.285 \\
\hline $43 \sim 84$ & 1.224 & $0.342 \sim 4.373$ & 0.756 \\
\hline $22 \sim 42$ & 0.838 & $0.311 \sim 2.259$ & 0.726 \\
\hline $8 \sim 21$ & reference & & \\
\hline
\end{tabular}

our and other studies [12]. Immature vascularization induces an increased susceptibility of the retina to oxidative damage. Therefore, our study enrolled infants with a GA of $24 \sim 29$ weeks. Furthermore, our study aimed to clarify the possible impact of aerosol therapy on ROP. Thus, we only investigated infants who received aerosol therapy before the development of ROP.

In this study, inhalants were delivered with $100 \%$ oxygen via a nebulizer. It is well documented that high oxygen saturation can increase the risk of ROP [21]. However, a lower target range of oxygenation may result in an increase in mortality [22]. Therefore, adequate oxygen during aerosol therapy is mandatory to maximize benefits and minimize harms. To reduce the potential risk of ROP, several factors should be considered while conducting aerosol therapy. Our data suggest that an oxygen blender or metered dose inhaler-spacer device may be needed for inhalation therapy to reduce excess oxygen exposure [23]. In addition, using the mechanical ventilator or a mesh nebulizer to produce the aerosol can decrease the fraction of oxygen concentration. Furthermore, the total time outside the target saturation range is associated with the development of ROP [16]. Thus, shortening the duration or frequency of high-oxygen inhalation may be helpful in decreasing the risk of ROP.

The role of oxygen in the development of ROP is complex. Many reports showed a reduction in ROP with supplemental oxygen in a later course of treatment after ROP had already developed [24, 25]. Accordingly, aerosol therapy with pure oxygen may be fine when an infant already has ROP.

In this study, we did not focus on the medications used in aerosol therapy. One would question whether medicines such as acetylcysteine may have an impact on the development of ROP. Our study found no significant difference in ROP between inhalants with and without acetylcysteine (data not shown). Furthermore, it has been shown that acetylcysteine may have a protective effect against ROP [26]. Thus we believe that ROP is not simply modulated by inhaled medicines, although the potential effects of inhalation drugs cannot be completely ruled out.

In our study, the univariate analyses showed ROP was more common in infants with HFV, iNO, and prolonged intubation. However, the multivariate model did not find a significant correlation of ROP with these ventilation settings, which are in accordance with previous reports of meta-analysis illustrating that HFV and iNO did not increase the risk of ROP in preterm infants [27, 28].

There are limitations to our study. First, this study was a retrospective design. Randomized controlled trials are needed to determine the causal effect of aerosol therapy on ROP. Second, the effectiveness of aerosol therapy for premature neonates was not evidence-based [21]. No clear long-term benefits have been demonstrated yet. Third, we did not investigate the potential impact of delivery devices. Nevertheless, the delivery devices were not changed throughout the study period.

\section{Conclusion}

Aerosol therapy is increasingly administered to premature infants during the first hospital month. Possible adverse effects of aerosol therapy need to be elucidated. Our study implies an increased risk of ROP with aerosol medicines administrated using pure oxygen. Appropriate oxygen delivery may play a role in reducing the progression of ROP. Clinicians should use great caution when conducting aerosol therapy with excess oxygen in preterm infants.

\section{Abbreviations}

BPD: Bronchopulmonary dysplasia; GA: Gestational age; HFV: High frequency ventilation; iNO: Inhaled nitric oxide; NICU: Neonatal intensive care unit; ROP: Retinopathy of prematurity

\section{Authors' contributions \\ MCY, HFH, HLT and YHW conceived and developed the study. YWC assisted with coordinating the study and participated in data collection. MCY and YHW were responsible for the statistical analysis. All the authors were involved in drafting the manuscript. The final manuscript was read and approved by all the authors. \\ Funding \\ This work was supported by research grants from Chang Gung Memorial Hospital (CMRPG1F0182) and the Ministry of Science and Technology, \\ Taiwan (MOST 106-2314-B-182A-032- and MOST 105-2410-H-038-011-SSS). \\ These grants provided the funding of data analysis and manuscript writing}

Availability of data and materials

Please contact Yi-Hao Weng for data requests. 


\section{Ethics approval and consent to participate}

This study was approved by the Institutional Review Board of Chang Gung Memorial Hospital with a waiver of informed consent because all patient records were anonymized and de-identified prior to analysis (number 102-1170B).

\section{Consent for publication}

Not applicable.

\section{Competing interests}

The authors declare that they have no competing interests.

\section{Author details}

'Department of Respiratory Therapy, Chang Gung Memorial Hospital, Chang Gung University, Taoyuan, Taiwan. ${ }^{2}$ Master Program in Global Health and Development, College of Public Health, Taipei Medical University, Taipei, Taiwan. ${ }^{3}$ Department of Pediatrics, Chang Gung Memorial Hospital, Chang Gung University College of Medicine, 199 Dunhua North Road, Taipei 105, Taiwan.

Received: 18 October 2018 Accepted: 2 August 2019

Published online: 13 August 2019

\section{References}

1. Deng Q, Ou C, Chen J, Xiang Y. Particle deposition in tracheobronchial airways of an infant, child and adult. Sci Total Environ. 2018:612:339-46.

2. Mhanna MJ, Patel JS, Patel S, Cohn R. The effects of racemic albuterol versus levalbuterol in very low birth weight infants. Pediatr Pulmonol. 2009;44:778-83.

3. Fayon M, Tayara N, Germain C, Choukroun ML, De La Roque ED, Chene G, Breilh D, Marthan R, Demarquez JL. Efficacy and tolerance of high-dose inhaled ipratropium bromide vs terbutaline in intubated premature human neonates. Neonatology. 2007;91:167-73.

4. Rieger-Fackeldey E, Reinhardt D, Schulze A. Effects of inhaled formoterol compared with salbutamol in ventilated preterm infants. Pulm Pharmacol Ther. 2004:17:293-300.

5. Ng G, da Silva O, Ohlsson A. Bronchodilators for the prevention and treatment of chronic lung disease in preterm infants. Cochrane Database Syst Rev. 2016;12:CD003214.

6. Clouse BJ, Jadcherla SR, Slaughter JL. Systematic review of inhaled bronchodilator and corticosteroid therapies in infants with bronchopulmonary dysplasia: implications and future directions. PLoS One. 2016;11:e0148188.

7. Slaughter JL, Stenger MR, Reagan PB, Jadcherla SR. Inhaled bronchodilator use for infants with bronchopulmonary dysplasia. J Perinatol. 2015;35:61-6.

8. Yeh TF, Lin HC, Chang CH, Wu TS, Su BH, Li TC, Pyati S, Tsai CH. Early intratracheal instillation of budesonide using surfactant as a vehicle to prevent chronic lung disease in preterm infants: a pilot study. Pediatrics. 2008:121:e1310-8.

9. Lauterbach R, Szymura-Oleksiak J, Pawlik D, Warchol J, Lisowska-Miszczyk I, Rytlewski K. Nebulized pentoxifylline for prevention of bronchopulmonary dysplasia in very low birth weight infants: a pilot clinical study. J Matern Fetal Neonatal Med. 2006;19:433-8.

10. Rubin BK. Aerosol medications for treatment of mucus clearance disorders. Respir Care. 2015;60:825-9.

11. Icard BL, Rubio E. The role of mucoactive agents in the mechanically ventilated patient: a review of the literature. Expert Rev Respir Med. 2017;11:807-14.

12. Hakeem AH, Mohamed GB, Othman MF. Retinopathy of prematurity: a study of prevalence and risk factors. Middle East Afr J Ophthalmol. 2012;19:289-94.

13. Chen M, Citil A, McCabe F, Leicht KM, Fiascone J, Dammann CE, Dammann O. Infection, oxygen, and immaturity: interacting risk factors for retinopathy of prematurity. Neonatology. 2011;99:125-32.

14. Tokuhiro Y, Yoshida T, Nakabayashi Y, Nakauchi S, Nakagawa Y, Kihara M, Mitsufuji N, Kizaki Z. Reduced oxygen protocol decreases the incidence of threshold retinopathy of prematurity in infants of $<33$ weeks gestation. Pediatr Int. 2009;51:804-6.

15. Rasoulinejad SA, Montazeri M. Retinopathy of Prematurity in Neonates and its Risk Factors: A Seven Year Study in Northern Iran. Open Ophthalmol J. 2016:10:17-21.

16. Kaufman DA, Zanelli SA, Gurka MJ, Davis M, Richards CP, Walsh BK. Time outside targeted oxygen saturation range and retinopathy of prematurity. Early Hum Dev. 2014;90(Suppl 2):S35-40.
17. Perlman JM, Wyllie J, Kattwinkel J, Wyckoff MH, Aziz K, Guinsburg R, Kim HS, Liley HG, MildenhallL, Simon WM, Szyld E, Tamura M, Velaphi S. Neonatal Resuscitation Chapter, Collaborators: Part 7: Neonatal Resuscitation: 2015 International Consensus on Cardiopulmonary Resuscitation and Emergency Cardiovascular Care Science With Treatment Recommendations. Circulation. 2015;132(Suppl 1):S204-41.

18. Dolovich MB, Dhand R. Aerosol drug delivery: developments in device design and clinical use. Lancet. 2011;377:1032-45.

19. An International Committee for the Classification of Retinopathy of, Prematurity. The International Classification of Retinopathy of Prematurity revisited. Arch Ophthalmol. 2005;123:991-9.

20. Kandasamy J, Carlo WA. Pharmacologic therapies IV: other medications. In: Goldsmith JP, Karotkin EH, Keszler M, Suresh GK, editors. Assisted Ventilation of the Neonate: An Evidence-Based Approach to Newborn Respiratory Care. 6th ed. Philadelphia: Elsevier; 2016. p. 366-79.

21. Manley BJ, Kuschel CA, Elder JE, Doyle LW, Davis PG. Higher rates of retinopathy of prematurity after increasing oxygen saturation targets for very preterm infants: experience in a single center. J Pediatr. 2016;168:242-4.

22. SUPPORT Study Group of the Eunice Kennedy Shriver NICHD Neonatal Research Network. Target ranges of oxygen saturation in extremely preterm infants. N Engl J Med. 2010;362:1959-69.

23. Khalaf MN, Hurley JF, Bhandari V. A prospective controlled trial of albutero aerosol delivered via metered dose inhaler-spacer device (MDI) versus jet nebulizer in ventilated preterm neonates. Am J Perinatol. 2001;18:169-74.

24. Colaizy TT, Longmuir S, Gertsch K, Abramoff MD, Klein JM. Use of a supplemental oxygen protocol to suppress progression of retinopathy of prematurity. Invest Ophthalmol Vis Sci. 2017;58:887-91.

25. The STOP-ROP Multicenter study group. Supplemental Therapeutic Oxygen for Prethreshold Retinopathy Of Prematurity (STOP-ROP), a randomized, controlled trial. I: primary outcomes. Pediatrics. 2000;105:295-310.

26. El-Hadidy AR, El-Mohandes EM, Asker SA, Ghonaim FM. A histological and immunohistochemical study of the effects of $\mathrm{N}$-acetyl cysteine on retinopathy of prematurity by modifying insulin-like growth factor-1. Biotech Histochem. 2016;91:401-11.

27. Barrington KJ, Finer N, Pennaforte T. Inhaled nitric oxide for respiratory failure in preterm infants. Cochrane Database Syst Rev. 2017;1:CD000509.

28. Cools $F$, Offringa M, Askie LM. Elective high frequency oscillatory ventilation versus conventional ventilation for acute pulmonary dysfunction in preterm infants. Cochrane Database Syst Rev. 2015;3:CD000104.

\section{Publisher's Note}

Springer Nature remains neutral with regard to jurisdictional claims in published maps and institutional affiliations.

Ready to submit your research? Choose BMC and benefit from:

- fast, convenient online submission

- thorough peer review by experienced researchers in your field

- rapid publication on acceptance

- support for research data, including large and complex data types

- gold Open Access which fosters wider collaboration and increased citations

- maximum visibility for your research: over $100 \mathrm{M}$ website views per year

At BMC, research is always in progress.

Learn more biomedcentral.com/submissions 